\title{
Comparative effectiveness of surgical and Non- surgical management for patients with single level lumbar disc herniation in terms of symptom severity and quality of life
}

\author{
Sangoli Shashank $D N B^{1}$
}

${ }^{1}$ Medical Trust Hospital, Kochi, India

Date of submission: $30^{\text {th }}$ March 2020

Date of acceptance: $10^{\text {th }}$ January 2021

Date of publication: $1^{\text {st }}$ March 2021

\section{Abstract}

Introduction: Sciatica is one of the most severe form of low back pain, with a lifetime prevalence of approximately 30 percent. To assess the short-term and long-term efficacy of surgical and conservative care in the incidence of sciatic symptoms and quality of life in standard clinical settings in patients with lumbar disc herniation.

Material and method: It is a retrospective study conducted at Medical Trust Hospital, Kochi who underwent micro lumbar discectomy for single level lumbar disc herniation, and of those with the same diagnosis but who refused surgery or were still waiting for the surgery to be scheduled. The patients were divided into two groups as Group A- treated surgically and Group B - awaiting for surgery and managed non-surgically. Cases between 2060 years of age, male or female, with low back pain and lower limb radiculopathy, positive signs of root tension (SLRT between 30-70 degrees or severe femoral root stress), associated neurological dysfunction (with respect to corresponding abnormal reflexes, reduced sensation in dermatomal distribution or weakness in myotomal distribution) and multiple disc herniation cases if only one of the level was symptomatic, were included. The study excluded patients with scoliosis of more than 15 degrees, segmental instability, spondylolisthesis, spine or tumor infection, psychiatric disease, refusal of patients and age $<20$ and $>60$ years. After obtaining the written informed consent from all recruited patients, a clinical evaluation by means of established questionnaires which included the Short Form 36 (SF36), 16 the Oswestry Disability Index (ODI), 17 and the visual analog scale for pain (VAS). Patients were grouped into: Group A, for those who had already undergone surgical treatment and Group B, those awaiting surgery.

Results: Total 60 patients fulfilling the inclusion criteria were included in present study. Mean age of the patients in Group A was $36.7 \pm 5.8$ and in Group B was $37.01 \pm 5.56$ years. Male preponderance was observed in our study with male to female ratio of 1.7:1. At the time of admission, patients in both the groups suffered similar scale of pain and agony. The VAS and ODI did not show significant difference in the pain and disability in both group of patients. During follow-up of 6month and 2 years, surgically treated patients showed a significant improvement in the scores of VAS and ODI. Also the SF-36 also showed a similar results and was better in patients treated by surgery contrary with conservative treatment.

Conclusion: The study concluded with positive benefits from surgery with a reduction in pain reported in the lower limbs (VAS leg with $\mathrm{p}<0.05$ ) and improved function (Oswestry with $\mathrm{p}<0.05$ ); however, it did not show any much significant change in quality of life according to the SF-36 scale.

Key words: Oswestry Disability index (ODI), Lower Back Pain, Lumbar Disc Herniation, Sciatica, Short Form-36 (SF-36), Visual Analog Scale (VAS)

Access this article online
Website: https://www.nepjol.info/index.php/NJN
DOI: https://doi.org/10.3126/njn.v18i1.28281
HOW TO CITE
Shashank S. Comparative effectiveness of surgical and Non-
surgical management for patients with single level lumbar disc
herniation in terms of symptom severity and quality of life. NJNS.
2021;18(1):28-32.

${ }^{1}$ ORCID id: 0000-0002-5796-8886

\author{
Address for correspondence: \\ Dr. Sangoli Shashank \\ Specialist Neurosurgeon \\ Gulbarga Institute of Medical Sciences, \\ Kalaburagi, Kochi, India \\ E-mail: shashanknsangoli@gmail.com \\ Phone: +91-6282610210 \\ Copyright (C) 2021 Nepalese Society of Neurosurgeons (NESON) \\ ISSN: 1813-1948 (Print), 1813-1956 (Online)
}




\section{Comparative effectiveness of surgical and Non-surgical management for patients with single level lumbar disc ...}

\section{Introduction}

$\mathrm{S}$ ciatica is a disorder caused by lumbar nerve root compression or irritation. Common symptoms and signs include unilateral leg pain, reduced muscle strength in the myotomal distribution, and sensory deficits. ${ }^{1,2}$ Sciatica is one of the severe form of low back pain, with a lifetime prevalence of as much as 30 percent. ${ }^{3,4}$

According to the Institute for Clinical Systems Improvement guideline on adult acute and subacute back pain, ${ }^{5}$ the mainstays of therapy are reassurance and patient education, ${ }^{6,7}$ activity modification to limit disk loading, non-steroidal anti-inflammatory drugs (NSAIDs) and/acetaminophen, ${ }^{8,9,10}$ and a gradual return to physical activity.

The aim of nonsurgical treatment for acute low back pain is a return to baseline functional status while effectively controlling pain. In general, the effect sizes for established conservative interventions in acute low back pain are fairly small, and there is limited evidence at best for several adjunct interventions such as acupuncture, spinal manipulation, transcutaneous electrical nerve stimulation, or lumbar traction. ${ }^{11,12}$

Lumbar discectomy remains one of the most commonly performed procedures. ${ }^{13,14}$ and the outcomes are considered excellent for patients who are good surgical candidates.

For patients without severe neurological deficits, however,determining who should undergo surgery is not as clear. Because most cases ( $>85 \%$ at 6 weeks) ofback pain (including those from disk herniation) are self-limited and would resolve with nonsurgicaltreatment in the first place, there is no reliable way to predict which patients will benefit from surgicalintervention. ${ }^{15}$

The aim of this study is to compare the efficacy of thesurgical treatment in patients who have single level lumbar disc herniation with the patients who have a surgical indication but were still waiting to undergo the procedure or wanting the conservative treatment.

Objectives:To assess the short-term and longterm efficacy of surgical and conservative care in the management of sciatic symptoms and quality of life in standard clinical settings in patients with lumbar disc herniation.

\section{Material and Methods}

Following approval by the Ethical committee from the Institutional Review Board, a retrospective search was done, of the medical records of patients in medical followup at the Medical Trust Hospital, Kochi who underwent micro lumbar discectomy for single level lumbar disc herniation, and of those with the same diagnosis but who refused surgery or were still waiting for the surgery to be scheduled.

Cases between 20-60 years of age, both male and female, with low back pain with lower limb radiculopathy, positive signs of root tension (SLRT between 3070 degrees or severe femoral root stress), associated neurological dysfunction (asymmetric depressed reflex, reduced sensation in dermatomal distribution or weakness in myotomal distribution) and multiple herniation cases if only one of the hernia was symptomatic, were included. The study excluded patients with scoliosis of more than 15 degrees, segmental instability, spondylolisthesis, spine or tumor infection, psychiatric disease, refusal of patients and age $<20$ and $>60$ years. All patients recruited had to fill the consent and a clinical evaluation by means of established questionnaires which included the Short Form 36 (SF36), ${ }^{16}$ the Oswestry Disability Index (ODI), ${ }^{17}$ and the visual analog scale for pain (VAS).Then were grouped into: Group A, for those who had already undergone surgical treatment and Group B, those awaiting surgery.

The Short Form (36) Health Survey is a 36-item, patient-reported survey of patient health. The SF-36 consists of eight scaled scores (functional capacity, physical aspects, pain, general state of health, vitality, social aspects, emotional aspects, and mental health.), which are the weighted sums of the questions in their section. Each scale is directly transformed into a 0-100 scale on the assumption that each question carries equal weight. The lower the score the more disability. The higher the score the less disability

The ODI is used for functional assessment of the lumbar spine, incorporating measurements of pain and physical activity. The scale consists of 10 questionswith six alternatives. The first question evaluates pain intensity andthe other nine, the effect of pain on day-to-day activities.

Statistical analysis:All the data was collected and data entry was done in Excel. Data analysis is conducted using version 23 of SPSS Software. Quantitative data is presented with the aid of Mean \pm SD. Significance of mean difference was analysed using student t-test. P-value less than 0.05 is considered significant.

\section{Results}

Total 60 patients fulfilling the inclusion criteria were included in present study. The patients were divided into two groups as Group A- treated surgically and Group B - awaiting for surgery and managed non-surgically. Mean age of the patients in Group A was $36.7 \pm 5.8$ and in Group B was $37.01 \pm 5.56$ years. Male preponderance 


\section{Shashank et al}

was observed in our study with male to female ratio of 1.7:1 [Table 1].

At the time of admission, patients in both the groups suffered similar scale of pain and agony. The VAS and ODI did not show significant difference in the pain and disability in both group of patients [Table 2].

There is a significant improvement in the visual analogue score and Oswestry disability index in patients treated by surgical procedure compared to patients who are treated on conservative basis. $(\mathrm{p}<0.05)$ There was little evidence of a difference in quality of life between groups throughout the study; however the SF-36 score had significant difference at 6 month post-surgery. $(p<0.05)$ [Table 3].

\section{Discussion}

We found in present study that the surgical treatment, when compared to conservative treatment reduced the severity of sciatica symptoms and pain. It also improved the quality of life of patients with the lumbar disc herniation in the short term and long term. Quick Pain reduction was seen in the patients who received surgical treatment but the difference between the groups was no longer present after 3 months of both treatment modalities.

Patients in surgical group reported less physical impairments at the 6 month and 2 years of follow-up. Faster improvement in pain symptoms in patients treated with surgical treatment is a common finding in comparison with patients treated conservatively with lumbar disc

\begin{tabular}{|c|c|c|c|c|}
\hline & & Group A $(n=30)$ & Group B $(n=30)$ & p-value \\
\hline Age in years & & $36.7 \pm 5.8$ & $37.01 \pm 5.56$ & 0.821 \\
\hline \multirow[t]{2}{*}{ Gender } & Male & 18 & 20 & \\
\hline & Female & 12 & 10 & \\
\hline
\end{tabular}

Table 1: Demographic details of the patients

\begin{tabular}{|c|c|c|c|}
\hline & $\begin{array}{c}\text { Surgical } \\
\text { Mean } \pm \text { SD }\end{array}$ & $\begin{array}{c}\text { Conservative } \\
\text { Mean } \pm \text { SD }\end{array}$ & p-value \\
\hline Visual analog scale for pain (VAS) & $7.23 \pm 0.77$ & $7.20 \pm 0.88$ & 0.476 \\
\hline Oswestry Disability Index (ODI) & $29.77 \pm 3.12$ & $29.93 \pm 3.22$ & 0.866 \\
\hline Physical & $28.65 \pm 1.62$ & $28.7 \pm 1.95$ & .323 \\
\hline Short Form 36 & $52.0 \pm 5.0$ & $50.0 \pm 1.5$ & $<.001^{*}$ \\
\hline
\end{tabular}

Table 2: Baseline characteristics of patients

\begin{tabular}{|c|c|c|c|}
\hline & $\begin{array}{c}\text { Surgical } \\
\text { Mean } \pm \text { SD }\end{array}$ & $\begin{array}{c}\text { Conservative } \\
\text { Mean } \pm \text { SD }\end{array}$ & p-value \\
\hline \multicolumn{4}{|l|}{ VAS } \\
\hline 6 month & $2.73 \pm 0.6$ & $2.8 \pm 0.71$ & .369 \\
\hline 2 years & $1.77 \pm 0.9$ & $2.1 \pm 0.935$ & $.03 *$ \\
\hline \multicolumn{4}{|l|}{ ODI } \\
\hline 6 month & $3.03 \pm 0.9$ & $2.8 \pm 0.66$ & $.05^{*}$ \\
\hline 2 years & $1.93 \pm 1.11$ & $2.19 \pm 1.0$ & $.02 *$ \\
\hline \multicolumn{4}{|c|}{ SF-36 Physical function } \\
\hline 6 month & $34.0 \pm 2$ & $38.4 \pm 2.05$ & .895 \\
\hline 2 years & $42.5 \pm 1.25$ & $44.0 \pm 2.0$ & $0.01 *$ \\
\hline \multicolumn{4}{|c|}{ SF-36 Mental Function } \\
\hline 6 month & $49.0 \pm 1.0$ & $46.4 \pm 1.95$ & $.005^{*}$ \\
\hline 2 years & $47.5 \pm 1.5$ & $46.65 \pm 1.17$ & 0.186 \\
\hline
\end{tabular}

Table 3: Patient characteristics in all follow-up assessments at 6 month and 2 years 
herniation. Previous studies also observed that back ache was reduced quickly with surgical treatment. ${ }^{13,18}$ Nonetheless, results concerning neurogenic symptoms, physical function and quality of life are not recorded in other observational studies as reliably. In line with other observational studies, short-and long-term effects of surgical treatment have been observed in these outcomes are beneficial. ${ }^{18}$

There was a significant improvement in the VAS and ODI in patients treated with surgical compared to the patient treated conservatively [Table 3]. These findings are in relation with previous studies conducted. However, we did not see much difference in the quality of life in the patients at the follow-up. But, patients treated with surgical procedure showed a better score in physical and mental status on SF-36 questionnaire. ${ }^{19}$

\section{Conclusion}

Although patients were more symptomatic at the entry, there was substantial overlapping of symptoms between the surgically treated patients and conservatively treated patient. Surgically treated patients with sciatica reported substantially greater improvement at the 2-year follow. This study concluded that patients with lumbar stenosis without spondylolisthesis benefits from surgery with a reduction in pain reported in the lower limbs (VAS leg with $\mathrm{p}<0.05$ ) and improved function (Oswestry with $\mathrm{p}<0.05$ ); however, it didnot show any much significant change in quality of life according to the SF-36 scale.

Conflict of Interest: None

Source(s) of support: None

\section{References}

1. Koes BW, van Tulder MW, Peul WC. Diagnosis and treatment of sciatica. BMJ. 2007 Jun 23;334(7607):1313-7. https://doi.org/10.1136/ bmj.39223.428495.BE

2. Pinto RZ, Maher CG, Ferreira ML, Ferreira PH, Hancock M, Oliveira VC, McLachlan AJ, Koes B. Drugs for relief of pain in patients with sciatica: systematic review and meta-analysis. BMJ. 2012 Feb 13;344:e497. https://doi.org/10.1136/bmj.e497

3. Konstantinou K, Dunn KM. Sciatica: review of epidemiological studies and prevalence estimates. Spine2008;33:2464-72. https://doi.org/10.1097/ BRS.0b013e318183a4a2.

4. Stafford MA, Peng P, Hill DA. Sciatica: a review of history,epidemiology, pathogenesis, and the role of epidural steroid injection in management. $\mathrm{Br} \mathrm{J}$
Anaesth2007;99:461-73. https://doi.org/10.1093/bja/ aem 238

5. Goertz M, Thorson D, Bonsell J, et al. Adult acute and subacute low back pain. 15th ed. Institute for Clinical Systems Improvement: Bloomington, MN; 2012.

6. Heymans MW, van Tulder MW, Esmail R, Bombardier C, Koes BW. Back schools for non-specific low-back pain. Cochrane Database of Systematic Reviews 2004, Issue 4. Art. No.: CD000261. https://doi. org/10.1002/14651858.CD000261.pub2

7. Engers A, Jellema P, Wensing $M$, van der Windt DA, Grol R, van Tulder MW. Individual patient education for low back pain. Cochrane Database Syst Rev. 2008 Jan 23;2008(1):CD004057. https:/doi. org/10.1002/14651858.CD004057.pub3.

8. Yakhno N, Guekht A, Skoromets A, et al. Analgesic efficacy and safety of lornoxicamquickrelease formulation compared with diclofenac potassium: randomised, double-blind trial in acute low back pain. Clin Drug Investig. 2006;26(5):267-277. https://doi. org/10.2165/00044011-200626050-00004

9. Roelofs PD, Deyo RA, Koes BW, et al. Nonsteroidal anti-inflammatory drugs for low back pain: an updated Cochrane review. Spine. 2008;33:1766-1774. https:// doi.org/10.1097/BRS.0b013e31817e69d3.

10. Hancock MJ, Maher CG, Latimer J, et al. Can predictors of response to NSAIDs be identified in patients with acute low back pain? Clin J Pain. 2009;25:659-665. https://doi.org/10.1097/ AJP.0b013e3181a7ee3a.

11. McIntosh G, Hall H. Low back pain (acute). BMJ ClinEvid. 2011;2011:1102. PMID: 21549023

12. Keller A, Hayden J, Bombardier C, et al. Effect sizes of non-surgical treatments of nonspecific low-back pain. Eur Spine J. 2007;16:1776-1788. https://doi. org/10.1007/s00586-007-0379-x

13. Atlas SJ, Chang Y, Kammann E, et al. Long-term disability and return to work among patients who have a herniated lumbar disc: the effect of disabil- ity compensation. J Bone Joint Surg Am 2000;82:4-15. https://doi.org/10.2106/00004623-200001000-00002

14. Deyo RA, Weinstein JN. Low back pain. N Engl J Med 2001;344:363-70. https://doi.org/10.1056/ NEJM200102013440508

15. Fager CA. Observations on spontaneous recovery from intervertebral disc herniation. Surg Neurol. 1994;42:282-286. https://doi.org/10.1016/00903019(94)90393-x

16. Ciconelli RM, Ferraz MB, Santos W, Meinão, Lent MR. SF36 quality of life questionnaire (Brazil SF36). Rev Bras Rheumato. 1999; 39 (3): 143-50. 


\section{Shashank et al}

17. Fairbank JC, PynsentPB,TheOswestry Disability Index. Spine 2000 Nov 15;25(22):2940-52. https:// doi.org/10.1097/00007632-200011150-00017

18. Atlas SJ, Deyo RA, Keller RB, et al. The Maine Lumbar Spine Study, Part II. 1-year outcomes of surgical and nonsurgical management of sciatica.spine.1996;21:1777-86 https:/doi. org/10.1097/00007632-199608010-00011
19. Gugliotta M, Costa BR, Dabis E, Theiler R, Juni P, ReixhenbachS et.al. surgical versus conservative treatment for lumbar disc herniation: a prospective cohort study. BMJ open. 2016;6:e012938. https://doi. org/10.1136/bmjopen-2016-012938. 